DOI 10. 18307/2020. 0515

(C) 2020 by Journal of Lake Sciences

\title{
亚热带地区典型水库流域氮、磷湿沉降及入湖贡献率估算”
}

\author{
余博识 ${ }^{1}$, 梁 亮 $^{1}$, 郑丹萍 ${ }^{1}$, 刘会萍 $^{2}$, 童秀华 $^{3}$, 唐华峰 $^{1}$, 徐克铭 $^{1 * *}$ \\ ( 1 : 浙江省绍兴市汤浦水库有限公司, 绍兴 312364) \\ (2: 浙江省舟山开源供水有限责任公司,舟山 316021) \\ (3: 浙江省绍兴市公用事业集团有限公司, 绍兴 312000)
}

\begin{abstract}
摘 要: 为了探究汤浦水库流域氮、磷湿沉降对水库水体营养的贡献率, 本研究对 2014-2015 年的汤浦水库流域 4 个采 样点的雨水及 3 条溪流进行样品收集, 测定其中磷和不同形态氮的质量浓度, 分析汤浦水库流域大气湿沉降中氮、磷营养 盐的分布特征, 并估算氮、磷营养盐湿沉降对汤浦水库人库负荷的贡献率. 结果表明: 湿沉降中总氮 (TN) 平均浓度为 $1.02 \pm 0.58 \mathrm{mg} / \mathrm{L}$, 氨氮、硝态氮和有机氮浓度占 TN 浓度的比例分别为 $60.65 \% 、 34.07 \%$ 和 $5.28 \%$; 总磷 ( TP) 平均浓度为 $0.033 \pm 0.028 \mathrm{mg} / \mathrm{L} .4$ 个采样点湿沉降中氮、磷浓度均表现为冬春季 (少雨季) 高、夏秋季 (多雨季) 低. 空间上, 王化点位的 各形态氮和总磷浓度显著高于其他 3 个采样点. TN 和 TP 年均湿沉降通量约为 18.15 和 $0.62 \mathrm{~kg} /\left(\mathrm{hm}^{2} \cdot \mathrm{a}\right)$, 年均沉降总量 为 834.94 和 $28.39 \mathrm{t}$; 库区 TN 和 TP 水面湿沉降量为 24.14 和 $0.82 \mathrm{t}$, 直接贡献率占河流输人的 $1.77 \%$ 和 $3.07 \%$. 湿沉降来 源的氮、磷营养盐随河流输人的间接贡献率为 $8.3 \%$ 和 $4.6 \%$. 综上所述, 氮、磷湿沉降是水库外源营养的重要输人部分, 深 人掌握其时空分布特征及人库贡献率是进一步加强流域管理和减轻水库外源营养输人的重要前提.
\end{abstract}

关键词: 汤浦水库流域;湿沉降;氮; 磷; 贡献率

\section{Wet atmospheric deposition of nitrogen and phosphorus and estimation of their contribu- tions to the lake in typical subtropical reservoir basins*}

YU Boshi ${ }^{1}$, LIANG Liang ${ }^{1}$, ZHENG Danping $^{1}$, LIU Huiping ${ }^{2}$, TONG Xiuhua ${ }^{3}$, TANG Huafeng ${ }^{1} \&$ XU Keming $^{1 * *}$

(1: Shaoxing Tangpu Reservoir Co., Ltd., Zhejiang Province, Shaoxing 312364, P.R.China)

(2: Zhoushan Kaiyuan Water Supply Co., Ltd., Zhejiang Province, Zhoushan 316021, P.R.China)

(3: Shaoxing Public Utilities Group Co., Ltd., Zhejiang Province, Shaoxing 312000, P.R.China)

Abstract : To understand seasonal and spatial wet deposition characteristics of nutrients input to the Tangpu Reservior Basin, precipitation samples at four sites and stream water samples at three sites were collected from the basin during 2014-2015. The mass concentration of total nitrogen $(\mathrm{TN})$, nitrate nitrogen $\left(\mathrm{NO}_{3}^{-}-\mathrm{N}\right)$, ammonia nitrogen and total phosphorus $(\mathrm{TP})$ in the wet deposition were measured, and the precipitation characteristics of nitrogen and phosphorus nutrients, the deposition rates and their contributions compared with their counterparts from external loading of streams to the reservoir were studied. The results showed that the annual wet deposition concentration of TN was $1.02 \pm 0.58 \mathrm{mg} / \mathrm{L}$, and the percentages of ammonium, nitrate and organic nitrogen contributed $60.65 \%, 34.07 \%$ and $5.28 \%$ of TN, respectively. The annual wet deposition concentration of TP was $0.033 \pm 0.028 \mathrm{mg} / \mathrm{L}$. Seasonally, the concentrations of TN and TP in wet deposition were higher in winter and spring than in summer and autumn. Spatially, the concentrations of TN and TP were the highest at Wanghua site. The annual wet deposition rates of TN and TP were about 18.151 and 0.62 $\mathrm{kg} /(\mathrm{ha} \cdot \mathrm{a})$, and their average annual budgets reached 834.94 and $28.39 \mathrm{t}$, respectively. The wet depositions of water surface into Tangpu Reservoir were 24.14 and $0.82 \mathrm{t}$, and the direct contributions as $1.77 \%$ and $3.07 \%$ of the stream input. The indirect contributions of nitrogen and phosphorus from wet deposition sources accounted for $8.3 \%$ and $4.6 \%$ of the stream input. In summary, the nutrient load from the wet deposition plays a crucial role in the nutrient input of reservoirs. Understanding the nutrient load from the wet

* 2019-08-24 收稿;2019-09-07 收修改稿.

** 通信作者;E-mail: sxtpsk@126.com. 
deposition will help us to better manage the reservoir basin and reduce the external nutrient loads to the basin.

Keywords: Tangpu Reservoir Basin; wet atmosphere deposition; nitrogen; phosphorus ; contribution

现代工业的快速发展、农业化肥的大量应用、生物质燃烧和高密度人口的经济社会活动, 释放了大量的 氮磷化合物和颗粒物 ${ }^{[1-2]}$. 在重力作用下, 大气中水溶性或颗粒态氮磷被雨、雪、雹等降水过程冲刷至地面进 人生态系统, 并伴随着土壤侵蚀, 加剧河流、湖泊和水库等水体的富营养化 ${ }^{[2-3]}$. 因此, 作为流域非点源污染 因素之一的大气氮、磷湿沉降及其生态环境效应引起了广泛关注.

我国逐步建立起监测大气氮干湿沉降的全国氮沉积监测网 ( NNDMN $)^{[4]}$ 和基于中国生态系统研究网 $\left(\right.$ CERN) 的氮、磷沉降监测体系 ${ }^{[5]}$. 于贵瑞等研究认为全国总氮 ( TN) 湿沉降在 2005 年到达峰值后逐渐下 降 $^{[6]}$. 湿沉降的氮、磷浓度和通量有着明显的季节变化、空间分布 ${ }^{[7-8]}$ 和年际差异, 结合氨氮与硝态氮的比值 $\left(\mathrm{NH}_{3}-\mathrm{N} / \mathrm{NO}_{3}^{-}-\mathrm{N}\right)$ 可以判断主要来源于农业源或城市源 ${ }^{[9-10]}$. 在大尺度空间上, 利用 HYSPLIT 模型的后向轨 迹模型模拟分析不同降水气团来源和输送路径 ${ }^{[8,10-13]}$, 王小刚通过逐小时跟踪湿沉降中 $\mathrm{NH}_{4}^{+} 、 \mathrm{NO}_{3}^{-}$等离子浓 度的变化规律, 认为湿沉降对不同大气污染物净化效率不同, 离子浓度变化也与降雨量、污染物排放量密切 相关 ${ }^{[13]}$. 大气湿沉降氮、磷营养随径流人湖 (间接贡献) 是一个复杂的过程, 赵婷婷等通过人河系数对干湿 沉降、生活污染源、畜禽养殖污染物、农业种植业等 7 种污染源进行解析 ${ }^{[14]}$; 王金杰等引用美国宾夕法尼亚 洲的氮输出系数 (输出率) 对汉江金水河进行估算 ${ }^{[15]}$; 徐冯迪等运用不同土地利用类型的径流输出系数开 展估算 ${ }^{[16]}$; 考虑到营养物的迁移转化、土壤固持、植物吸收等因素, 张峰在径流系数的基础上, 根据离河距离 建立了校正系数 ${ }^{[17]}$; 考虑氮的降解和保留, Whitalla 等根据子流域距离建立了到达河口的保留比例 ${ }^{[18]}$. 还有 研究引人 $\delta^{15} \mathrm{~N}$ 和 $\delta^{18} \mathrm{O}$ 双同位素技术, 解析大气来源的氮污染贡献占比 ${ }^{[19-21]}$.

汤浦水库作为虞绍平原重要饮用水源地之一, 担负着杭州湾大湾区建设的部分水源供给, 水质保证是 汤浦水库的生命线. 为探索大气氮、磷污染占水库外源污染输人的比重, 本文在汤浦水库上游 4 个乡镇的主 要 3 条人库溪流中部设置大气湿沉降采样点 4 处, 溪流汇人口设置水质采样点 3 处. 对流域内大气湿沉降及 人库溪流营养情况进行初步观测, 分析大气湿沉降中氮的数量、形态, 研究氮、磷输人的时空分布规律, 估算 湿沉降对汤浦水库水体氮、磷负荷的直接和间接贡献量, 为流域水质管理提供科学依据.

\section{1 研究区域概况与研究方法}

\section{1 研究区域概况}

研究区为浙江省绍兴市汤浦水库流域, 汤浦水库坝址位于小舜江下游的绍兴市上虞区汤浦镇, 控制流 域集水面积 $460 \mathrm{~km}^{2}$, 水库水域面积 $13.64 \mathrm{~km}^{2}$. 汇人水库的河流主要有南溪、北溪、王化溪和万乔溪, 其中南 溪、北溪在库前汇成双江溪. 双江溪、王化溪和万乔溪的人库流量占水库总径流量的比例分别为 $75.4 \%$ 、 $13.3 \%$ 和 $4.3 \%$. 流域平均海拔高度 $263.5 \mathrm{~m}$, 土壤类型主要为红壤, 土地利用方式主要包括林地、水田、旱地、 茶园和果园, 原始山林占流域面积的 $75 \%$. 流域多年平均气温 $17.1^{\circ} \mathrm{C}$, 平均降水量 $1530 \mathrm{~mm}$. 汤浦水库流域 属亚热带季风性气候区, 四季分明, 光照充足, 雨量丰沛, 温暖湿润. 由于处于中亚热带与北亚热带的过渡 区, 且地形较复杂, 小气候差异明显, 降雨量季节分配不均匀, 其中 3-9 月 7 个月的雨量占全年降水量的 $80 \%$,梅雨季平均每年 6 月中旬人梅, 7 月上旬出梅, 雨量相对集中;秋季常受台风影响, 形成暴雨事件. 流域 2014 年和 2015 年属于丰水年, 年降雨量分别为 1711 和 $1991 \mathrm{~mm}$. 王化点位地处谷地的村落中心, 北部、南 部均有较大面积农田, 两边有百米山体; 王坛点位西部为山林, 东部为湿地, 地势较低, 属于盆地边缘, 离集 镇和农田有 $1 \mathrm{~km}$ 的距离, 集镇发达, 污染物不易扩散; 稽东点位东部为山林, 西部为农田和集镇, 位于集镇 边缘; 谷来点位周边为开垦山地, 从事农业种植、经济苗木种植等, 地势较高, 位于半山腰, 西部 $200 \mathrm{~m}$ 为村 落, 东部 $1 \mathrm{~km}$ 为集镇. 4 个雨样点附近均有公路穿过.

\section{2 采样点设置与样品分析}

在汤浦水库流域综合考虑了流域范围、空间分布及采样便利等因素, 在上游 4 个乡镇, 主要干流中部, 分别设置了具有代表性的大气氮、磷湿沉降采样点共 4 个 (图 1), 在屋顶设置人工雨量计, 依据天气预报, 在 降雨前打开雨量计的盖子, 人工采集雨水样品. 于次日将收集到的满足检测用量 $(>500 \mathrm{~mL})$ 的雨水样品转 
移到 $2.5 \mathrm{~L}$ 聚乙烯塑料吉中, 同时采集人库溪流(南溪、 北溪、王化溪) 水样各 $2.5 \mathrm{~L}$, 送往检测单位检测. 2014 年 1 月-2015 年 12 月共采集大气湿沉降样品 60 个, 溪 流样品 48 个. 每月还另外采集一次溪流样品进行检测, 样品共 72 个. 面雨量数据来自汤浦水库公司自有雨量 自动监测系统,由 9 个监测点位按各自权重综合所得.

雨水样品分析指标为: 总磷 ( TP ) 、 $\mathrm{TN} 、 \mathrm{NH}_{3}-\mathrm{N}$ 和 $\mathrm{NO}_{3}^{-}$-N. TP 浓度测定参照《水质 总磷的测定 锄酸铵分 光光度法》(GB 11893-1989), TN 浓度测定参照《水质 总氮的测定 碱性过硫酸钾消解紫外分光光度法》( HJ 636-2012), $\mathrm{NO}_{3}^{-}-\mathrm{N}$ 浓度测定参照《水质 无机阴离子的 测定 离子色谱法》( HJ/T84-2001), $\mathrm{NH}_{3}-\mathrm{N}$ 浓度测定 参照《水质氨氮的测定 纳氏试剂分光光度法》 $(\mathrm{HJ}$ 535-2009), 委托绍兴市水环境科学研究院有限公司进 行样品检测.

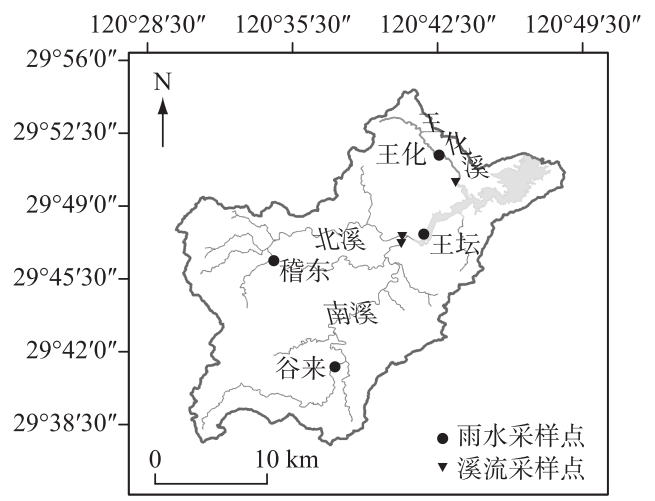

图 1 汤浦水库流域采样点分布

Fig.1 Distribution of sampling sites in Tangpu Reservoir Basin

\section{3 数据处理}

无机氮 $(\mathrm{IN})$ 浓度为 $\mathrm{NH}_{3}-\mathrm{N}$ 与 $\mathrm{NO}_{3}^{-}-\mathrm{N}$ 浓度之和. 有机氮 $(\mathrm{ON})$ 浓度为 $\mathrm{TN}$ 与 $\mathrm{IN}$ 浓度之差 ${ }^{[22]}$.

氮、磷湿沉降通量的计算公式 ${ }^{[23]}$ 为:

$$
F=\sum(R \cdot C) / 100
$$

式中, $F$ 为氮、磷的年湿沉降通量 $\left(\mathrm{kg} /\left(\mathrm{hm}^{2} \cdot \mathrm{a}\right)\right), R$ 为年内逐月降雨量 $(\mathrm{mm}), C$ 为雨水中 $\mathrm{TN} 、 \mathrm{TP}$ 浓度 $(\mathrm{mg} /$ L).

氮、磷湿沉降输出量的计算公式为:

$$
P=\sum\left(\mu \cdot F_{1} \cdot S_{1} / 10\right)+\sum\left(F_{2} \cdot S_{2} / 10\right)
$$

式中, $P$ 为湿沉降输出的营养物量 $(\mathrm{t}) ; F_{1}$ 为月湿沉降通量 $\left(\mathrm{kg} /\left(\mathrm{hm}^{2} \cdot \mathrm{a}\right)\right) ; S_{1}$ 为上游流域面积 $\left(\mathrm{km}^{2}\right) ; F_{2}$ 为月 水面湿沉降通量 $\left(\mathrm{kg} /\left(\mathrm{hm}^{2} \cdot \mathrm{a}\right)\right) ; S_{2}$ 为水域面积 $\left(\mathrm{km}^{2}\right) ; \mu$ 为流失系数.

数据采用 Excel 2016 软件整理,采用 Origin 2018 软件作图,地图采用 ArcGIS 10.2 软件绘制.

\section{2 结果与分析}

\section{1 湿沉降氮、磷浓度}

2014- 2015 年汤浦水库流域各采样点雨水 TN 浓度范围为 $0.15 \sim 2.47 \mathrm{mg} / \mathrm{L}$, 平均值为 $1.02 \pm 0.58 \mathrm{mg} / \mathrm{L}$; TP 浓度范围为 $0.005 \sim 0.112 \mathrm{mg} / \mathrm{L}$, 平均值为 $0.033 \pm 0.028 \mathrm{mg} / \mathrm{L}$ (图 2). 氮湿沉降通量约为 $18.15 \mathrm{~kg} /\left(\mathrm{hm}^{2} \cdot \mathrm{a}\right)$, 低于 本地区临界负荷 ${ }^{[24]}$, 磷湿沉降通量约为 $0.62 \mathrm{~kg} /\left(\mathrm{hm}^{2} \cdot \mathrm{a}\right)$.
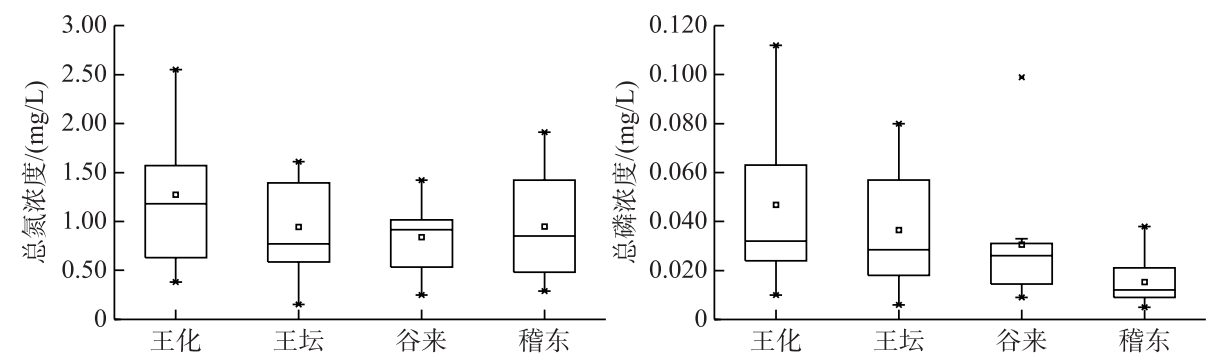

图 $22014-2015$ 年汤浦水库流域各采样点雨水的总氮和总磷浓度 （图中横线从下至上分别表示 $5 \% 、 25 \% 、 50 \% 、 75 \% 、 95 \%$ 分位数;棵平均值）

Fig. 2 Concentrations of total nitrogen and total phosphorus in rainwater at each site of Tangpu Reservoir Basin from 2014 to 2015 


\section{2 入库主要溪流氮、磷营养特征}

2014- 2015 年汤浦水库流域 3 条主要人库溪流 TN 浓度范围为 $0.82 \sim 4.81 \mathrm{mg} / \mathrm{L}$, 平均值为 $2.94 \pm 0.85$ $\mathrm{mg} / \mathrm{L} ; \mathrm{NH}_{3}-\mathrm{N}$ 浓度范围为 $0.05 \sim 0.60 \mathrm{mg} / \mathrm{L}$, 平均值为 $0.08 \pm 0.07 \mathrm{mg} / \mathrm{L} ; \mathrm{NO}_{3}^{-}-\mathrm{N}$ 浓度范围为 $0.6 \sim 4.3 \mathrm{mg} / \mathrm{L}$, 平 均值为 $2.52 \pm 0.77 \mathrm{mg} / \mathrm{L} ; \mathrm{TP}$ 浓度范围为 $0.12 \sim 0.30 \mathrm{mg} / \mathrm{L}$, 平均值为 $0.06 \pm 0.04 \mathrm{mg} / \mathrm{L}$ (图 3).

汤浦水库水环境保护的目标水质为 II 类, 《地表水环境质量标准》( GB 3838-2002) 中基本项目标准限 值对应的 TN 和 TP 限值分别为 0.5 和 $0.025 \mathrm{mg} / \mathrm{L}$, 大气湿沉降中氮、磷平均浓度分别是该标准限值的 2.04 和 1.32 倍, 湿沉降 $\mathrm{TN}$ 平均浓度达到该标准的 IV 类, TP 平均浓度达到该标准的 III 类. 径流氮、磷平均浓度分 别是该标准限值的 5.88 和 2.4 倍, 按该评价标准, 径流 $\mathrm{TN}$ 平均浓度为劣 $\mathrm{V}$ 类, $\mathrm{TP}$ 平均浓度为 $\mathrm{IV}$ 类. 径流及 湿沉降的高浓度氮、磷输人对汤浦水库水环境, 特别是水体富营养化会产生一定的影响.
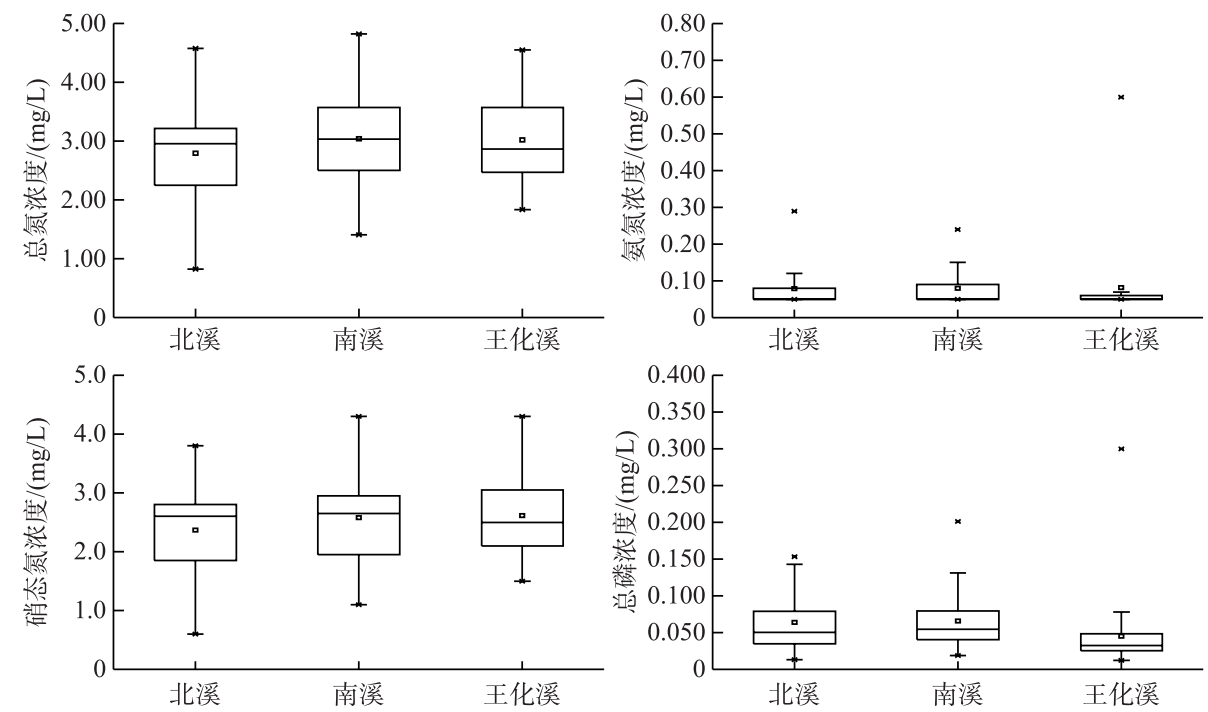

图 $32014-2015$ 年汤浦水库流域主要人库溪流氮、磷浓度

Fig. 3 Concentration of nitrogen and phosphorus in the main streams of Tangpu Reservoir Basin from 2014 to 2015

\section{3 雨水氮化学形态特征}

汤浦水库流域 $\mathrm{NH}_{3}-\mathrm{N} 、 \mathrm{NO}_{3}^{-}-\mathrm{N} 、 \mathrm{ON}$ 浓度占 $\mathrm{TN}$ 浓度的比例分别为 $60.65 \% 、 34.07 \%$ 和 $5.28 \%$ (表 1)，与洞 庭湖蒋家嘴 (JJZ) 点位类似 ${ }^{[25]}, 4$ 个采样点无机氮的比例均高于 $87 \%, \mathrm{NH}_{3}-\mathrm{N}$ 的比例均达 $55 \%$ 以上, 说明汤 浦水库流域大气氮湿沉降的主要成分是无机氮, 特别是 $\mathrm{NH}_{3}-\mathrm{N}$. 这与汤浦水库流域内汽车尾气排放、生物质 燃烧以及农林业施肥活动有关 ${ }^{[9,26]}$. 由表 1 可以看出 4 个采样点不同形态氮所占的比例存在一定的差异, $\mathrm{NH}_{3}-\mathrm{N}$ 比例在稽东最高 (66.34\%), $\mathrm{NO}_{3}^{-}-\mathrm{N}$ 比例在王坛最高 (38.3\%), $\mathrm{ON}$ 比例在王化最高 (12.41\%). ON 来 源于硝酸酯类化合物、森林等环境直接释放的还原型 (尿素等) 和颗粒型有机氮 (花粉、生物碎屑等) ${ }^{[27]}$. 研

表 1 汤浦水库流域雨水氮浓度及形态组成

Tab.1 Concentration and species composition of nitrogen in rainwater of Tangpu Reservoir Basin

\begin{tabular}{cccccccc}
\hline 采样点 & $\mathrm{TN} /(\mathrm{mg} / \mathrm{L})$ & $\mathrm{NH}_{3}-\mathrm{N} /(\mathrm{mg} / \mathrm{L})$ & $\mathrm{NO}_{3}^{-}-\mathrm{N} /(\mathrm{mg} / \mathrm{L})$ & $\mathrm{ON} /(\mathrm{mg} / \mathrm{L})$ & $\mathrm{NH}_{3}-\mathrm{N} / \%$ & $\mathrm{NO}_{3}^{-}-\mathrm{N} / \%$ & $\mathrm{ON} / \%$ \\
\hline 王化 & $1.37 \pm 0.73$ & $0.78 \pm 0.39$ & $0.42 \pm 0.21$ & $0.17 \pm 0.12$ & 56.93 & 30.66 & 12.41 \\
王坛 & $0.94 \pm 0.50$ & $0.52 \pm 0.34$ & $0.36 \pm 0.17$ & $0.06 \pm 0.09$ & 55.32 & 38.30 & 6.38 \\
谷来 & $0.75 \pm 0.34$ & $0.48 \pm 0.20$ & $0.26 \pm 0.11$ & $0.01 \pm 0.01$ & 64.00 & 34.67 & 1.33 \\
稽东 & $1.01 \pm 0.58$ & $0.67 \pm 0.40$ & $0.33 \pm 0.19$ & $0.01 \pm 0.02$ & 66.34 & 32.67 & 0.99 \\
平均值 & $1.02 \pm 0.58$ & $0.61 \pm 0.33$ & $0.35 \pm 0.17$ & $0.06 \pm 0.03$ & 60.65 & 34.07 & 5.28 \\
\hline
\end{tabular}


究区雨水中有机氮平均含量较低, 特别是谷来和稽东点位有机氮所占比例均低于 $2 \%$, 与其他地区相比, 汤 浦水库流域有机氮沉降比例要低于长乐江流域和金水河流域 ${ }^{[15,17]} .4$ 个采样点的 $\mathrm{NH}_{3}-\mathrm{N} / \mathrm{NO}_{3}^{-}-\mathrm{N}>1$, 说明均 以农业源为主 ${ }^{[26]}$, 其中王坛点比值最小 (1.44), 与其采样点附近城镇规模密切相关, 是其他采样点规模的 $3 \sim 5$ 倍, 比值向城市源偏移. 王化点位的谷地呈西北东南走向, 污染物扩散方向单一, 采样点附近个别月份 有零星的禽类养殖,会产生尿素和氨挥发,这都可能是 $\mathrm{NH}_{3}-\mathrm{N} 、 \mathrm{ON}$ 偏高的原因.

\section{4 湿沉降氮、磷浓度的时空变化特征}

2.4.1 湿沉降的时间变化特征 根据汤浦水库流域季节分布特点, 将年划分为春季 ( $3-5$ 月)、夏季 $(6-8$ 月)、秋季 (9-11月) 和冬季 (12-2 月). 由图 4 可以看出, 雨水的 $\mathrm{TN} 、 \mathrm{NO}_{3}^{-}-\mathrm{N}$ 和 $\mathrm{TP}$ 平均浓度在时间上呈现 较明显的季节性变化, $\mathrm{TN}$ 和 $\mathrm{NO}_{3}^{-}-\mathrm{N}$ 浓度在时间上的变化具有一致性, 以春、冬两季最高 (春季>冬季>秋季> 夏季), 且表现出夏、秋、冬季逐渐升高的特点, TN 浓度最低值出现在夏季 $(0.83 \pm 0.11 \mathrm{mg} / \mathrm{L})$, 与春季、冬季 呈显著差异 $(P \leqslant 0.05) ; \mathrm{NO}_{3}^{-}-\mathrm{N}$ 浓度最低值出现在夏季 $(0.27 \pm 0.23 \mathrm{mg} / \mathrm{L})$, 与春、冬季呈显著差异 $(P \leqslant$ $0.01) ; \mathrm{NH}_{3}-\mathrm{N}$ 浓度的季节性差异不显著; TP 浓度在不同季节的变化趋势表现为: 冬季>春季>夏季>秋季, 仅 春季与秋季差异显著 $(P \leqslant 0.05)$. 冬、春季降雨频率低强度小, 因长时间富集空气中氮、磷营养物质含量较 高, 一次降雨则雨水中氮、磷浓度较高; 夏、秋季降雨频率高强度大, 经多次冲刷雨水中氮、磷浓度较低 ${ }^{[28]}$. 总体而言, 汤浦水库流域雨水氮、磷浓度表现出冬、春季 (少雨季) 高于夏、秋季 (多雨季) 的特点, 和长三角 地区 ${ }^{[29]}$ 、重庆丰都 ${ }^{[9]}$ 的现象相同.
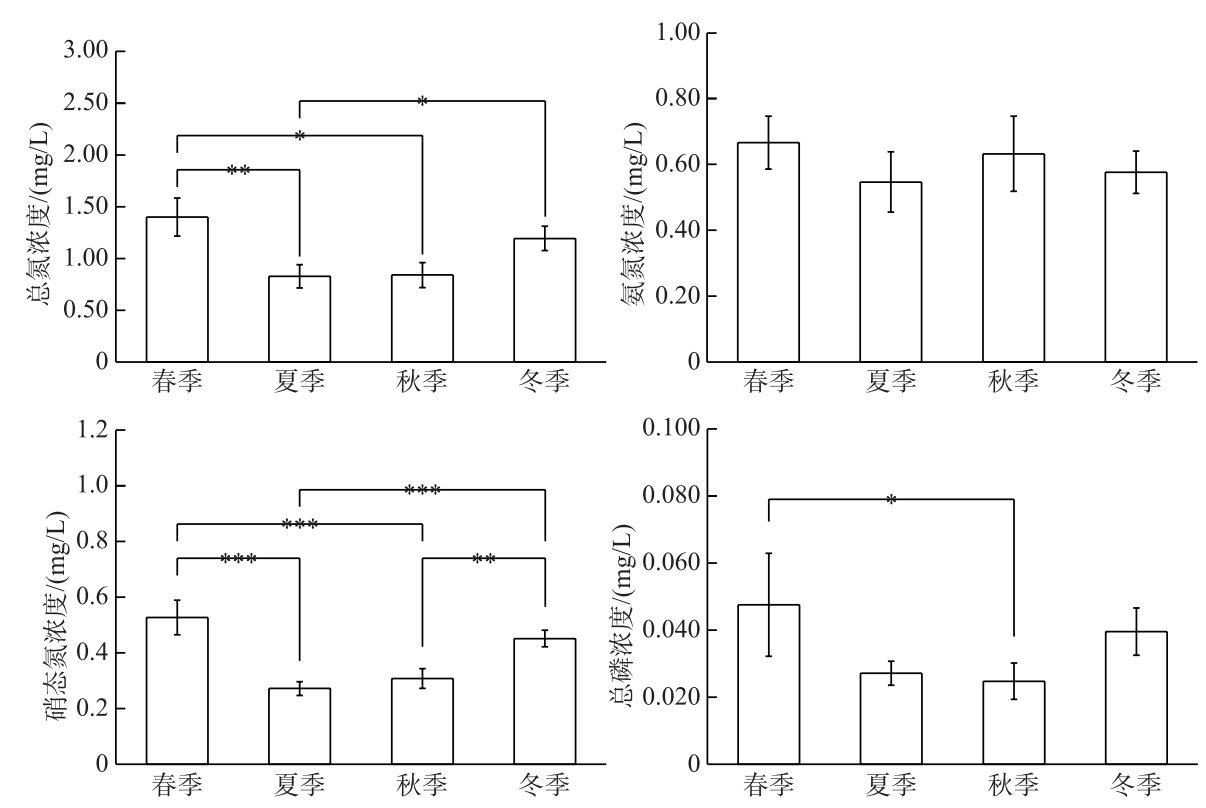

图 4 汤浦水库流域湿沉降氮、磷浓度的季节性变化

$(* P \leqslant 0.05, * * P \leqslant 0.01, * * * P \leqslant 0.001$; Fisher's LSD 检验)

Fig.4 Seasonal changes of nitrogen and phosphorus concentration in the wet deposition of Tangpu Reservoir Basin

2.4.2 湿沉降的空间变化特征 各采样点雨水的 TN、TP 平均浓度存在明显的时空差异特征,但 TN、TP 的空 间分布表现不同 (图 2, 表 1). 各采样点雨水的 $\mathrm{TN}$ 和 $\mathrm{NH}_{3}-\mathrm{N}$ 浓度空间分布一致:王化>稽东 $>$ 王坛 $>$ 谷来, $\mathrm{NO}_{3}^{-}-\mathrm{N}$ 和有机氮浓度大小为: 王化 $>$ 王坛 $>$ 稽东 $>$ 谷来, $\mathrm{TP}$ 浓度大小为: 王化 $>$ 王坛 $>$ 谷来 $>$ 稽东, 王化点位雨 水的各形态氮和 TP 浓度显著高于其他 3 个采样点 $(P<0.05)$. 汤浦水库流域是小尺度流域, 4 个采样点之间 的空间跨度较小, 雨水中的各形态氮和 TP 浓度在空间上表现出一定的变化趋势且达到显著水平 $(P<0.05)$, 主要是受到人为干扰作用的影响. 与其他地区比较, 氮湿沉降浓度高于植被覆盖度更高的金水河流域 ${ }^{[15]}$, 明显低于流域经济水平更高、单位人口数量更多的长乐江流域 ${ }^{[17]}$ 和太湖流域 ${ }^{[7]}$. 


\section{5 氮、磷湿沉降对汤浦水库直接贡献率的估算}

汤浦水库流域面积 $460 \mathrm{~km}^{2}$, 其中库面面积 $13.64 \mathrm{~km}^{2}$, 根据同期人库河流水质水量月度监测结果, 人库 的 $\mathrm{TN}$ 和 $\mathrm{TP}$ 年均污染负荷分别占 1364.83 和 $26.89 \mathrm{t}$, 其中 $\mathrm{NO}_{3}^{-}-\mathrm{N}$ 和 $\mathrm{NH}_{3}-\mathrm{N}$ 为 1137.11 和 $43.76 \mathrm{t}$, 分别占 $\mathrm{TN}$ 的 $83.3 \%$ 和 $3.2 \%$. 库面年均 TN 和 TP 湿沉降总量为 24.14 和 $0.82 \mathrm{t}$, 分别占河流人库负荷的 $1.77 \%$ 和 $3.07 \%$. 在气候相似的湖泊水库中, 依据表 2 计算可得, 占 $2.97 \%$ 流域面积的湖面, 滇池湿沉降输人的 TN、TP 负荷占 河流人湖总负荷的比例为 $1.71 \%$ 和 $3.55 \%$, 太湖为 $2.32 \% \sim 4.49 \%$ 和 $1.16 \% \sim 2.87 \%$, 巢湖为 $17.11 \%$ 和 $3.32 \%$, 其中汤浦水库 TN 湖面输人占人湖总负荷的比例与滇池类似, 是太湖的一半, 是巢湖的 $1 / 10$; 汤浦水库 TP 湖面输人占人湖总负荷的比例与滇池、巢湖差异较小, 是太湖低值年份的 2.7 倍. 翟水晶等研究认为氮、磷湿 沉降有助于北太湖夏、秋季蓝藻水华的发生 ${ }^{[30]}$, 因此在输人占比差距不明显的情况下, 湿沉降在汤浦水库可 能会产生相似的生态影响. 湖面输人占比的计算易受到人库水量、各支流人湖营养浓度、沉降浓度、沉降总 量等多种因子检测和统计的影响, 从而形成数据的偏差.

表 2 不同湖面湿沉降总氮和总磷年度沉降总量占人湖总负荷比例的比较

Tab.2 Comparison of annual wet deposition of total nitrogen and total phosphorus on different lake surfaces contribute to loading of lakes

\begin{tabular}{|c|c|c|c|c|c|c|c|c|}
\hline \multirow[t]{2}{*}{ 湖库名称 } & \multirow[t]{2}{*}{ 所在地区 } & \multirow{2}{*}{$\begin{array}{c}\text { 集雨 } \\
\text { 面积 } / \mathrm{km}^{2}\end{array}$} & \multirow{2}{*}{$\begin{array}{c}\text { 湖面 } \\
\text { 面积 } / \mathrm{km}^{2}\end{array}$} & \multirow{2}{*}{$\begin{array}{l}\text { 湖面在 } \\
\text { 流域中 } \\
\text { 占比 } / \%\end{array}$} & \multicolumn{2}{|c|}{$\begin{array}{c}\text { 湖面输人占 } \\
\text { 人湖总负荷比例 } / \%\end{array}$} & \multirow[t]{2}{*}{ 研究时间 } & \multirow[t]{2}{*}{ 文献 } \\
\hline & & & & & $\mathrm{TN}$ & $\mathrm{TP}$ & & \\
\hline 汤浦水库 & 浙江绍兴 & 460 & 13.64 & 2.97 & 1.77 & 3.07 & $2014-2015$ 年 & 本研究 \\
\hline 滇池 & 云南昆明 & 2920 & 311.39 & 10.66 & 6.14 & 12.76 & 2014 年 & {$[31]$} \\
\hline 太湖 & 江苏 & 约 19000 & 2338.1 & 12.31 & 18.6 & 11.9 & 2009 年 8 月一 2010 年 7 月 & {$[7]$} \\
\hline 太湖 & 江苏 & 约 19000 & 2338.1 & 12.31 & $14.3 / 9.6$ & $6.3 / 4.8$ & 2014 年 1 月－ 2015 年 12 月 & {$[32]$} \\
\hline 巢湖 & 安徽合肥 & 9130 & 825 & 6.88 & 39.61 & 7.69 & 2014 年 9 月－2016 年 1 月 & {$[33]$} \\
\hline 乌梁素海 ${ }^{1)}$ & 内蒙古 & 约 12000 & 285.38 & 2.38 & 15.0 & 13.47 & 2013 年 5 月－ 2013 年 10 月 & {$[34]$} \\
\hline 洱海 ${ }^{2)}$ & 云南大理 & 2565 & 249.8 & 2.08 & 32.31 & 32.68 & 2009 年 5 月－ 2010 年 4 月 & {$[35]$} \\
\hline 大河口水库 $^{3)}$ & 内蒙古 & 8684.54 & 17.26 & 0.14 & 4.39 & 4.72 & 2014 年 3 月一 2016 年 2 月 & {$[36]$} \\
\hline 大河口水库 & 内蒙古 & 8684.54 & 2.45 & 0.028 & 6.86 & - & 2016 年 & {$[37]$} \\
\hline 流溪河水库 & 广东从化 & 539 & 13 & 2.41 & 3.0 & 2.8 & 2007 年 9 月 -2008 年 12 月 & {$[38]$} \\
\hline
\end{tabular}

1) 含干沉降;2) 原文的湖面面积有误, 未更新;3) 原文 7 月干湿沉降总量修正后,重新计算所得.

\section{6 氮、磷湿沉降对汤浦水库间接贡献率的估算}

间接贡献率是从流域角度考虑氮、磷收支,输人项目包括: 大气沉降、化肥施用、生物固定、饲料输人等; 输出项目包括: 地表径流、淋失、氨挥发、反硝化、产品输出等 ${ }^{[39]}$; 土壤库属于多年积累的本底内源. 其中氮、 磷湿沉降属于流域营养输人元素之一,河流人库污染负荷量则是流域输出元素之一.

根据人库溪流水质 (图 3) 分析可知, 主要人库溪流中 $\mathrm{NH}_{3}-\mathrm{N}$ 和 $\mathrm{NO}_{3}^{-}-\mathrm{N}$ 浓度分别占年均 $\mathrm{TN}$ 浓度的 $2.1 \%$ 和 $85.7 \%$, 这与雨水氮组分中 $\mathrm{NH}_{3}-\mathrm{N}$ 占主导 (表 1) 有很大差异. 在稻麦轮作试验中也发现类似的现象, 坑面 水中 $\mathrm{NH}_{3}-\mathrm{N}$ 占 $\mathrm{TN}$ 的 $90 \%$ 以上, 渗漏水则以 $\mathrm{NO}_{3}^{-}-\mathrm{N}$ 为主, 占 $\mathrm{TN}$ 的 $85 \%$ 以上 ${ }^{[40]}$. 在大气湿沉降后, 降水中氮、 磷营养物质部分被土壤固持、植物吸收. 带有正电荷的 $\mathrm{NH}_{4}^{+}$被土壤吸附, 吸附能力为 $0.67 \sim 1.02 \mathrm{mg} / \mathrm{g}^{[41]}$, 吸 附量达到 $90 \%$ 平衡值只需 $10 \mathrm{~min}$ 左右, 解吸速率比吸附速率慢 18 倍 ${ }^{[42]}$. 土柱试验淋滤模拟证实 $\mathrm{NH}_{4}^{+}$迁移 较慢 ${ }^{[43]}$, HYDRUS-1D 软件模拟表明, $\mathrm{NH}_{4}^{+}$在弱透水层的迁移速度为 $0.06 \sim 0.36 \mathrm{~m} / \mathrm{a}^{[44]}$, 在毛竹林以 $1.31 \sim$ $4.78 \mathrm{mg} /(\mathrm{kg} \cdot \mathrm{d})$ 的硝化速率形成 $\mathrm{NO}_{3}^{-[45]}$. $\mathrm{NO}_{3}^{-}$在弱透水层的迁移速度为 $27.66 \sim 115.63 \mathrm{~m} / \mathrm{a}^{[44]}$, 较 $\mathrm{NH}_{4}^{+}$更容 易淋失. 在温度水分合适的条件下, 土壤中氮素的形式可以迅速转化, 最终达到动态平衡. 番茄黄瓜轮作试 验显示常规施肥组氮素淋失系数 (淋溶氮量占施氮量的\%) 平均为 $10.64 \%{ }^{[46]}$, 对大尺度面源氮负荷核算分 析认为, 2011 年全国种植业氮素(径流+淋洗) 总损失量占氮肥投人量的 $12.3 \%{ }^{[47]}$, 赵柳惠通过文献资料讨 论认为氮肥流失系数取 $11 \%$ 比较合适 ${ }^{[48]}$. 我们假设氮湿沉降也是一种肥料, 将 TN 流失系数取 $11 \%$, 根据公 式 (2) 计算, 流域大气湿沉降源的氮流失量为 $113.26 \mathrm{t}$,约占河流输出 TN 负荷的 $8.3 \%$,略低于表 3 中其他流 
域湿沉降来源年度输出量占人湖 (河流)负荷的比例. 研究显示汉江上游金水河流域氮湿沉降对水体贡献率 占流域氮肥贡献量为 $5.05 \% \sim 6.78 \%{ }^{[15]}$, 江西千烟洲香溪流域为 $4.3 \% \sim 5.7 \%{ }^{[49]}$. 由于径流中 $\mathrm{NO}_{3}^{-}-\mathrm{N}$ 占绝对 优势, 使用 $\delta^{15} \mathrm{~N}$ 和 $\delta^{18} \mathrm{O}$ 双同位素技术, 利用质量均衡模型、SIAR 模型等方法对硝酸盐来源进行定量识别, 研究表明大气沉降来源的 $\mathrm{NO}_{3}^{-}-\mathrm{N}$ 占人湖 (河流) 负荷的 $2 \% \sim 8 \%{ }^{[20-21]}$, 从而间接对 $\mathrm{TN}$ 进行溯源.

表 3 不同流域湿沉降来源的总氮和总磷年度输出量占人湖 (河流) 负荷比例的比较

Tab.3 Comparison of annual output of total nitrogen and total phosphorus from wet deposition in different basins to loading of lakes (rivers)

\begin{tabular}{|c|c|c|c|c|c|c|}
\hline 流域名称 & $\mathrm{TN}$ 占比 $/ \%$ & $\mathrm{TP}$ 占比 $/ \%$ & 估算方式 & 研究年度 & 文献 & 备注 \\
\hline 汤浦水库 & 8.3 & 4.6 & 流失系数 & $2014-2015$ 年 & 本研究 & \\
\hline 密云水库石匣 & 15.09 & - & 人河系数 & 2014 年 5 月－ 2015 年 1 月 & {$[50]$} & \\
\hline 江西千烟洲香溪 & 14.7 & 0.54 & 径流输出系数 & 2013 年 6 月－ 2014 年 5 月 & {$[16]$} & \\
\hline 浙江绍兴长乐江 & 36 & $0.4 \sim 1.1$ & 人河(校正)系数 & 2009 年 3 月- 2011 年 2 月 & {$[17]$} & \\
\hline 浙江绍兴长乐江 & 32 & - & 人河系数 & 2009 年 3 月- 2011 年 2 月 & {$[51]$} & SWAT 模型 \\
\hline 江苏宜兴漕桥河 & 24.23 & 9.38 & 人河系数 & 2009 年 & {$[14]$} & 含干沉降 \\
\hline 浙江杭嘉湖 & 32 & 7.7 & 人河系数 & 2013 年 9 月- 2014 年 8 月 & {$[12]$} & 含干沉降 \\
\hline 美国东海岸和墨西哥湾东部 & $10 \sim 40$ & - & & $1989-2000$ 年 & {$[52]$} & \\
\hline Waquoit Bay & $13 \sim 22$ & - & & 1992 年 & {$[53]$} & \\
\hline
\end{tabular}

土壤对磷有较强的吸附能力, 为 $0.3 \sim 0.6 \mathrm{mg} / \mathrm{g}^{[41]}$, 在降雨的过程中由于降雨侵蚀和径流侵蚀, 会增加土 壤中颗粒态磷的流失. 在对长乐江流域不同污染源分析表明大气磷沉降占污染物输人 (投排放) 总量的 $1 \%{ }^{[17]}$. 在对江西千烟洲香溪流域进行磷沉降研究认为, $\mathrm{P}$ 沉降输出系数为 $0.06 \% \sim 0.15 \%{ }^{[1]}$. 根据全国污染 源普查数据, 南方山地丘陵区肥料中 TP 流失系数为 $0.072 \% \sim 1.547 \%{ }^{[54]}$. 我们假设磷湿沉降也是一种肥料, 将 TP 流失系数取 $1.547 \%$, 则流域大气湿沉降源的磷流失量为 $1.25 \mathrm{t}$, 约占河流输出 TP 负荷的 $4.6 \%$, 明显 高于表 3 中千烟洲香溪流域和长乐江流域,略低于表 3 中漕桥河流域和杭嘉湖流域.

\section{3 结论与展望}

1) 从 $\mathrm{NH}_{3}-\mathrm{N} / \mathrm{NO}_{3}^{-}-\mathrm{N}$ 比值角度分析, 汤浦水库流域 4 个采样点湿沉降以农业源为主, 其中王坛点位的比 值向城市源偏移.

2) 在时间尺度上, 雨水氮、磷浓度呈现明显的季节性差异, 总体而言, 汤浦水库流域雨水氮、磷浓度表现 出冬、春季(少雨季) 高于夏、秋季 (多雨季) 的特点. 空间上, 王化点位的各形态氮和 TP 浓度显著高于其他 3 个采样点.

3) 氮、磷湿沉降占河流人库负荷的直接贡献率和间接贡献率均低于 $10 \%$, 间接贡献率较直接贡献率增 幅有限. 因此在河湖长制工作的外源污染物治理中, 需定期收集掌握不同土地利用类型等多污染源的数量 变化动态, 分析各污染源的贡献率, 甄别重点污染, 针对性地开展工程修复措施.

本文所收集的大气湿沉降基本可反映当时区域内湿沉降的时空变化, 但仍有许多不足. 大气湿沉降营 养通量受影响因素较多, 需结合气象条件多年跟踪分析, 并排除偶然性影响. 未来可引进湿沉降自动采样装 置, 弥补人工采样的不足. 对于洪水期流域营养输出应加密水质监测频次. 引人河流自净量, 结合降雨强度, 利用 SWAT 等分析模型, 更科学地开展估算分析.

致谢: 感谢斯坦福大学余继业老师、温州大学李仁辉老师、绍兴文理学院王斌梁老师等在论文修改中提供的 帮助.

\section{4 参考文献}

[ 1 ] Gao Y, Hao Z, Yang TT et al. Effects of atmospheric reactive phosphorus deposition on phosphorus transport in a subtropical watershed: A Chinese case study. Environmental Pollution, 2017, 226: 69-78.

[ 2 ] Luo LC, Qin BQ, Yang LY et al. Total inputs of phosphorus and nitrogen by wet deposition into Lake Taihu, China. 
Hydrobiologia, 2007, 581: 63-70.

[ 3 ] Koelliker Y, Totten LA, Gigliotti CL et al. Atmospheric wet deposition of total phosphorus in New Jersey. Water Air \& Soil Pollution, 2004, 154(1) : 139-150.

[ 4 ] Xu W, Zhang L, Liu X. A database of atmospheric nitrogen concentration and deposition from the nationwide monitoring network in China. Scientific Data, 2019, 6: 1-6.

[ 5 ] Zhu JX, Wang QF, He NP et al. Imbalanced atmospheric nitrogen and phosphorus depositions in China: Implications for nutrient limitation. Journal of Geophysical Research: Biogeosciences, 2016, 121(6) : 1605-1616.

[ 6 ] Yu GR, Jia YL, He NP et al. Stabilization of atmospheric nitrogen deposition in China over the past decade. Nature Geoscience, 2019, $12(6)$ : 424-429.

[ 7 ] Yu H, Zhang LL, Yan SW et al. Atmospheric wet deposition characteristics of nitrogen and phosphorus nutrients in Taihu Lake and contributions to the lake. Research of Environmental Sciences, 2011, 24(11): 1210-1219. [余辉, 张璐璐, 燕 姝雯等. 太湖氮磷营养盐大气湿沉降特征及入湖贡献率. 环境科学研究, 2011, 24(11): 1210-1219.]

[ 8 ] Wang JF, Zhou KJ, Wang XQ et al. Atmospheric nitrogen and phosphorous deposition in Hangiahu are. China Environmental Science, 2015, 35(9) : 2754-2763. [王江飞, 周柯锦, 汪小泉等. 杭嘉湖地区大气氮、磷沉降特征研究. 中国 环境科学, 2015, 35(9): 2754-2763.]

[ 9 ] Duan SH, Jiang YJ, Zhang YZ et al. Characteristics and sources of atmospheric inorganic nitrogen wet deposition in Xueyudong watershed, outer suburbs of Chongqing City. Environmental Science, 2018, 39(10) : 4479-4489. [段世辉, 蒋勇 军, 张远瞩等. 重庆远郊丰都雪玉洞流域大气无机氮湿沉降变化特征与来源分析. 环境科学, 2018, 39(10): 4479-4489.]

[10] Xing JW, Song JM, Yuan HM et al. Fluxes, seasonal patterns and sources of various nutrient species ( nitrogen, phosphorus and silicon) in atmospheric wet deposition and their ecological effects on Jiaozhou Bay, North China. Science of the Total Environment, 2017, 576(15): 617-627.

[11] Ma YB, Xu Q, Gao DQ et al. Composition of hydrogen and oxygen isotope in precipitation and source apportionment of water vapor in the wetland forest area of Tangpu Reservoir, Zhejiang Province. Forest Research, 2018, 31(3): 37-44. [马迎 宾, 徐庆, 高德强等. 汤浦水库湿地森林区大气降水氢氧同位素特征及水汽来源. 林业科学研究, 2018, 31(3): 37-44.]

[12] Wang JF. Atmospheric deposition of nitrogen and its effect on the water environment in the Hanhjiahu area [Dissertation]. Hangzhou: Zhejiang University of Technology, 2015. [王江飞. 杭嘉湖大气氮、磷沉降特征及其对水环境的影响 [学 位论文]. 杭州: 浙江工业大学, 2015.]

[13] Wang XG. Chemical composition and atmosphere pollutant source of wet deposition in Chang'an District, Xi'an City [Dissertation]. Xi'an: Northwest University, 2018. [王小刚. 湿沉降化学组成与大气污染源研究 [学位论文]. 西安: 西 北大学, 2018.]

[14] Zhao TT, Li QY, Lu LQ et al. Analysis of water environmental pollution in plain river network region in small watershed of Caoqiao River. Transactions of the Chinese Society of Agricultural Engineering, 2011, 27(S2): 170-175. [赵婷婷, 李秋 艳, 陆丽巧等. 漕桥河小流域平原河网地区水环境污染分析. 农业工程学报, 2011, 27(S2) : 170-175.]

[15] Wang JJ, Zhang KR, Wu C. Wet deposition of atmospheric nitrogen of the Jinshui watershed in the upper Hanjiang river. Environmental Science, 2014, 35(1) : 66-72. [王金杰, 张克荣, 吴川等. 汉江上游金水河流域氮湿沉降. 环境科学, $2014,35(1): 66-72$.

[16] Xu FD, Gao Y, Dong WY et al. Impact of atmospheric nitrogen and phosphorus wet deposition on nitrogen and phosphorus export and associated water quality: a case study of forest watershed in the red soil area, Southern China. Acta Ecologica Sinica, 2016, 36(20): 6409-6419. [徐冯迪, 高扬, 董文洣等. 我国南方红壤区氮磷湿沉降对森林流域氮磷输出 及水质的影响. 生态学报, 2016, 36(20): 6409-6419.]

[17] Zhang F. Atmospheric deposition of nitrogen and phosphorus and its contribution in the regional nutrients circulation in Changle river watershed [Dissertation]. Hangzhou: Zhejiang University, 2011. [张峰. 长乐江流域大气氮、磷沉降及其 在区域营养物质循环中的贡献 [学位论文]. 杭州: 浙江大学, 2011.]

[18] Whitalla D, Hendricksonb B, Paerlb H. Importance of atmospherically deposited nitrogen to the annual nitrogen budget of the Neuse River estuary, North Carolina. Environment International, 2003, 29(2) : 393-399.

[19] Deutsch B, Mewes M, Liskow I et al. Quantification of diffuse nitrate inputs into a small river system using stable isotopes of oxygen and nitrogen in nitrate. Organic Geochemistry, 2006, 37(10) : 1333-1342. 
[20] Zhao QL, Ma HY, Ren YF et al. $\delta^{15} \mathrm{~N}^{-\mathrm{NO}_{3}^{-}}$and $\delta^{18} \mathrm{O}-\mathrm{NO}_{3}^{-}$tracing of nitrate sources in Beijing Urban Rivers. Environmental Science, 2016, 37 (5): 1692-1698. [赵庆良，马慧雅，任玉芬等. 利用 $\delta^{15} \mathrm{~N}^{-\mathrm{NO}_{3}^{-}}$和 $\delta^{18} \mathrm{O}-\mathrm{NO}_{3}^{-}$示踪北京城区河 流硝酸盐来源. 环境科学, 2016, 37(5) : 1692-1698. ]

[21] Xue DM, De BB, Van CO et al. Use of a bayesian isotope mixing model to estimate proportional contributions of multiple nitrate sources in surface water. Environmental Pollution, 2012, 161: 43-49.

[22] Song HH, Jiang CM, Yu WT. Basic features and monitoring methodologies of atmospheric nitrogen deposition. Chinese Journal of Applied Ecology, 2014, 25 (2) : 599-610. [ 宋欢欢, 姜春明, 宇万太. 大气氮沉降的基本特征与监测方法. 应用生态学报, 2014, 25(2): 599-610.]

[23] Chen NW, Hong HS, Zhang LP. Wet deposition of atmospheric nitrogen in Jiulong River watershed. Environmental Science, 2008, 29(1) : 38-46. [陈能汪, 洪华生, 张珞平. 九龙江流域大气氮湿沉降研究. 环境科学, 2008, 29(1): 38-46.]

[24] Liu XJ, Duan L, Mo JM et al. Nitrogen deposition and its ecological impact in China: An overview. Environmental Pollution, 2011, 159(10) : 2251-2264.

[25] Zhang Y, Liu CM, Liu XJ et al. Atmospheric nitrogen deposition around the Dongting Lake, China. Atmospheric Environment, 2019, 207: 197-204.

[26] Zhao X, Yan XY, Xiong ZQ et al. Spatial and temporal variation of inorganic nitrogen wet deposition to the Yangtze River Delta Region, China. Water Air \& Soil Pollution, 2009, 203(1) : 277-289.

[27] Shi JH, Gao HW, Zhang J. Atmospheric organic nitrogen deposition and significance in marine ecosystem. Advances in Earth Science, 2006, 21(7): 721-729. [石金辉, 高会旺, 张经. 大气有机氮沉降及其对海洋生态系统的影响. 地球 科学进展, 2006, 21(7): 721-729.]

[28] Li L. Nitrogen and phosphorus loading from different sources in Dianchi lake and its contributions of different components [Dissertation]. Taiyuan: North University, 2016. [李乐. 滇池不同来源氮磷负荷及形态组成贡献 [学位论文]. 太原: 中北大学, 2016.]

[29] Chen ZL, Huang T, Huang XH et al. Characteristics, sources and environmental implications of atmospheric wet nitrogen and sulfur deposition in Yangtze River Delta. Atomspheric Environment, 2019, 219: 116904.

[30] Zhai SJ, Yang LY, Hu WP. Observations of atmospheric nitrogen and phosphorus deposition during the period of algal bloom formation in Northern Lake Taihu, China. Environmental Management, 2009, 44(3) : 542-551.

[31] Ren JG, Jia HB, Jiao LX et al. Characteristics of nitrogen and phosphorus forming in atmospheric deposition in Dianchi Lake and their contribution to lake loading. Environmental Science, 2019, 40(2) : 582-589. [任加国, 贾海斌, 焦立新 等. 滇池大气沉降氮磷形态特征及其入湖负荷贡献. 环境科学, 2019, 40(2) : 582-589.]

[32] Qiu M. Study on atmospheric deposition of nitrogen and phosphorus and simulating experiment of self-purification of water body in Lake Taihu [Dissertation]. Guangzhou: Jinan University, 2017. [ 邱敏. 太湖氮磷大气沉降及水体自净模拟实 验研究 [学位论文]. 广州: 暨南大学, 2017.]

[33] Wei DX, Li X, Zhao YH et al. Analyses of atmospheric nitrogen and phosphorus deposition at Hefei Science Island and its impact on Chaohu Lake. Journal of Hefei University of Technology: Natural Science, 2018, 41(9) : 1259-1266. [魏东霞, 李璇, 赵禹恒等. 合肥科学岛大气氮磷沉降及对巢湖影响的分析. 合肥工业大学学报: 自然科学版, 2018,41 (9) : 1259-1266.]

[34] Yin LL. Spatial-temporal distribution and atmospheric nutritive salt and heavy metals into the lake of Wuliangsuhai Lake [Dissertation]. Hohhot: Inner Mongolia Agricultural University, 2014. [尹琳琳. 乌梁素海大气氮、磷营养盐及重金属 沉降的分异规律与人湖量核算 [学位论文]. 呼和浩特: 内蒙古农业大学, 2014.]

[35] Zhang T. Research on the spatio-teraporal distribution of the concentrations of nitrogen and phosphorus and exogenous fluxes in Erhai Lake [Dissertation]. Dali: Dali University, 2011. [张态. 洱海氮磷时空分布特征及其外源负荷研究 [学 位论文]. 大理: 大理学院, 2011.]

[36] Zhang XJ, Lu JP, Ma TL et al. Wet deposition of atmospheric nitrogen and phosphorus and its impact on water environment of reservoir in Sand source area. Ecology and Environmental Sciences, 2017, 26(12): 2093-2101. [张晓晶, 卢俊 平, 马太玲等. 大气氮磷湿沉降特征及对沙源区水库水环境的影响. 生态环境学报, 2017, 26(12) : 2093-2101.]

[37] Zhang WR. A study on the Dahekou Reservoir nitrogen pollution characteristics and source apportionment by isotope technology [Dissertation]. Hohhot: Inner Mongolia Agricultural University, 2017. [张文瑞. 大河口水库氮污染特征及同位 素源解析研究 [ 学位论文]. 呼和浩特: 内蒙古农业大学, 2017.] 
[38 ] Lin GE. The dynamics and budget of nitrogen and phosphorus in Reservoir Liuxihe [Dissertation]. Guangzhou: Jinan University, 2009. [ 林国恩. 流溪河水库氮磷营养盐动态与收支分析 [学位论文]. 广州: 暨南大学, 2009.]

[39] Chen NW, Hong HS, Zhang LP et al. Nitrogen sources and exports in an agricultural watershed in Southeast China. Biogeochemistry, 2008, 87(2) : 169-179.

[40] Tang H, Qiu WG, Zhou X et al. Study on nitrogen losses characteristics and control countermeasures of rice-wheat rotation. Yellow River, 2010, 32(6): 64-66, 68. [唐浩, 邱卫国, 周噮等. 稻麦轮作条件下氮素流失特性及控制对策研究. 人民黄河, $2010,32(6): 64-66,68$.

[41] Wei Y. Studies on pollutant reduction of storm water runoff through topsoil [Dissertation]. Xi'an: Xi'an University of Architecture and Technology, 2014. [魏渘. 土壤表层对径流污染物的削减效应研究 [学位论文]. 西安: 西安建筑科技 大学, 2014.]

[42] Sun DZ, Li XQ, Pan XF. Ammonia absorption/desorption behavior in soil. Environmental Science \& Technology, 2007, 30 (8) : 16-18, 111, 116. [孙大志, 李绪谦, 潘晓峰. 氨氮在土壤中的吸附/解吸动力学行为的研究. 环境科学与技 术, $2007, \mathbf{3 0}(8): 16-18,111,116$.

[43] Ruan XH, Wang C, Zhu L. Migration and transformation of nitrogen in water logged aeration zone of soil. Journal of Hehai University, 1996, 24(2): 51-55. [ 阮晓红, 王超, 朱亮. 氮在饱和土壤层中迁移转化特征研究. 河海大学学报, 1996, 24(2): 51-55.]

[44] Miao JJ, Ma Z, Liu HW et al. Evaluation of the vulnerability of a leaky aquifer considering the retardation effect of an aquitard for specific pollutants: case study in the Tongzhou Plain, China. Hydrogeology Journal, 2020, 28: 687-701.

[45] Liu QR, Qi LH, Hu X et al. Effects of nitrogen fertilization on nitrification and denitrification in Phyllostachys edulis forests. Journal of Nanjing Forestry University: Natural Sciences Edition, 2017, 41(1): 82-88. [刘琦莣, 漆良华, 胡璇等. 氮肥对毛竹林土壤硝化和反硝化作用的影响. 南京林业大学学报: 自然科学版, 2017, 41(1): 82-88.]

[46] Liu XT, Zhao Y, Luo JH et al. Fertilization modes affect soil nitrogen loss in tomato-cucumber rotation systemand vegetable yield. Chinese Agricultural Science Bulletin, 2019, 35(4): 7-14. [刘晓䀐, 赵营, 罗健航等. 不同施肥管理模式对番 茄-黄瓜轮作体系土壤氮素流失及蔬菜产量的影响. 中国农学通报, 2019, 35(4): 7-14.]

[47] Xia YQ, Yang WX, Shi WM et al. Estimation of non-point source N emission in intensive cropland of China. Journal of Ecology and Rural Environment, 2018, 34(9): 782-787. [夏永秋, 杨旺金金, 施卫明等. 我国集约化种植业面源氮发生 量估算. 生态与农村环境学报, 2018, 34(9) : 782-787.]

[48] Zhao LH. The temporal and spatial characteristic of agriculture non-point source pollution and its economic factors in Zhejiang province [Dissertation]. Hangzhou: Zhejiang Gongshang University, 2015. [ 赵柳惠. 浙江省农业面源污染时空特 征及经济驱动因素分析 [学位论文]. 杭州 : 浙江工商大学, 2015.]

[49] Hao Z, Gao Y, Zhang JZ et al. Characteristics of atmospheric nitrogen wet deposition and associated impact on N transport in the watershed of red soil area in southern China. Environmental Science, 2015, 36(5): 1630-1638. [郝卓, 高扬, 张 进忠等. 南方红壤区氮湿沉降特征及其对流域氮输出的影响. 环境科学, 2015, 36(5) : 1630-1638.]

[50] Wang HX, Pang SJ, Wang XY et al. Atmospheric nitrogen dry and wet deposition in small catchment. Environmental Science, 2018, 39(12): 5365-5374. [王焕晓, 庞树江, 王晓燕等. 小流域大气氮干湿沉降特征. 环境科学, 2018, 39 (12) : 5365-5374.]

[51] Deng OP, Sun SY, Lv J. Nitrogen non-point source pollution identification based on ArcSWAT in Changle River. Environmental Science, 2013, 34(4) : 1284-1290. [邓欧平, 孙嗣昒, 吕军. 基于 ArcSWAT 模型的长乐江流域非点源氮素 污染源识别和分析. 环境科学, 2013, 34(4) : 1284-1290.]

[52] Paerl HW, Dennis RL, Whitall DR. Atmospheric deposition of nitrogen: implications for nutrient over-enrichment of coastal waters. Estuaries, 2002, 25(4): 677-693.

[53] Clark HD, Kremer JN. Estimating direct and episodic atmospheric nitrogen deposition to a coastal waterbody. Marine Environmental Research, 2005, 59(4) : 349-366.

[54] The First China Pollution Source Census Leading Group Office of State Council ed. Manual on fertilizer loss coefficient of agricultural pollution source of the first China pollution source census, 2009: 51-113. [国务院第一次全国污染源普查 领导小组办公室. 第一次全国污染源普查农业污染源肥料流失系数手册, 2009: 51-113.] 